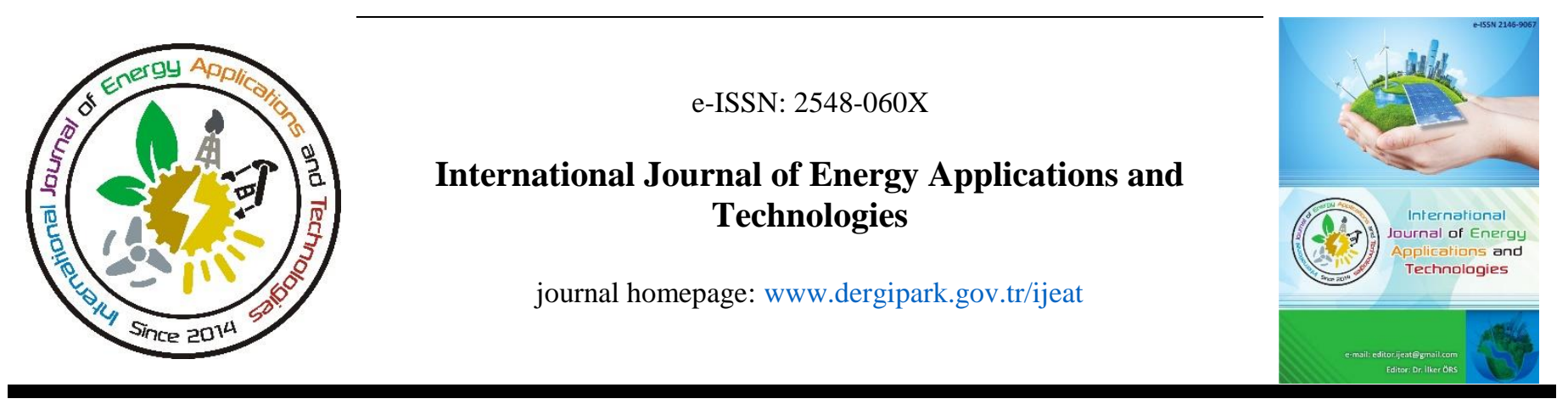

Original Research Article

\title{
A comparison of PSO and Fmincon methods for finding optimum operating speed and time values in trams
}

\author{
Mine Sertsöz*, Mehmet Fidan \\ Eskişehir Technical University Voc. School of Transportation 26140, Eskisehir, Turkey
}

\author{
ARTICLE INFO \\ * Corresponding author \\ msertsoz@eskisehir.edu.tr \\ Received September 23, 2020 \\ Accepted May 24, 2021 \\ Published by Editorial Board \\ Members of IJEAT \\ (C) This article is distributed by \\ Turk Journal Park System under \\ the CC 4.0 terms and conditions. \\ doi: 10.31593/ijeat.799129
}

\begin{abstract}
All the studies in urban railways gained importance with the requirement of developing in this area. However, not only technological development but also energy-saving conditions have great importance. One of these efficiency conditions is to know the optimum operating conditions. There are two electronic drive-warning systems. These warning systems are Driver Advisory System (DAS) and Automatic Train Operation (ATO), which are algorithm-based. To enrich these algorithms with meta-heuristic methods provides that it can be adapted to the changing operating conditions. Thus, flexible management can be achieved.

In this study, the Particle Swarm meta-heuristic and Fmincon which is a nonlinear programming solver in MATLAB methods are used to calculate optimum driving speed, acceleration, cruising, coasting, and full braking times under different operating conditions. Comparative optimization results of these selected methods are presented. Thus, attention is drawn to the efficiency in driving technique with different optimization methods. Specific speed-specific driving time matches obtained can be used to develop innovative driving warning systems.
\end{abstract}

Keywords: Energy efficiency in railways; Particle swarm; Fmincon; Optimization; Drive warning systems

\section{Introduction}

Using energy-efficient driving methods, it is thought that there is a $10 \%$ saving potential with considering all the traffic. Energy meters, of course, have much more accurate results than simulation consumption data, but sometimes it is not possible to take these measurements, especially when the train is still in the design phase, simulation is a great help. It is known that both electronic driver-warning systems are successful to determine the optimum driving solution correctly. These are the Driver Advisory System (DAS) and Automatic Train Operation (ATO); It should be noted that it is a success because their algorithms are planned correctly. Algorithms are often determined on convergence and computation times, but it is recommended that many algorithms are used when solving a problem and the best solution is compared by comparing these methods since it provides convergence over optimum rather than only possible solutions. According to the efficient driving theory, it is known that saving electricity is very serious. This ratio is an investment-free productivity tool created by paying attention only to the driver of the vehicle, without any investment.

The remarkable ones of the studies carried out to develop warning systems using metaheuristic methods are as follows: These studies [10, 11] focuses on minimizing energy consumption and traveling using the Indicator-Based Evolutionary Algorithm (IBEA). Another study [8] GA algorithm uses a Minimum-Allele-Reserve-Keeper (MARK) mutation scheme, to reduce processing time. Solution results use a cost function based on two parameters: schedule time and energy consumption. In [9], the search for an optimum speed profile, with energy consumption minimization, uses a GA together with an ANN. In [12] the authors present another example with GA: speed profile determination based on a multi-population GA. In [13] a PSO-based algorithm, 
with a multi-objective function, was implemented to find the Pareto front for energy and trip time. In [14] the authors present an algorithm that is a combination between GA and SA, a so-called Genetic Simulated Annealing Algorithm. It outputs the speed, position and time vectors, and energy consumption of the obtained speed profile. Some stations of the Eskisehir light rail served for algorithm performance tests.

The planning of this study: Energy Efficiency Driving Methods and their importance in rail systems; used applications in this area and an overview of the metaheuristic methods used to develop Energy Efficiency Driving Methods is given in the Introduction section. General information on driving regimes of vehicles and the importance of speed in energy consumption are given in Driving Regimes of Vehicles section. Particle Swarm is a meta-heuristic method and the theory of this method is given in the Particle Swarm Theory section. Minimizing the energy consumption speed must be minimized therefore speed minimization model is created aim of Particle Swarm Method. This part is given in the Proposed Model for Speed Optimization section. Lastly, the results, out comings, benefits of this study, and studies that can be handled in the future are handled in the Conclusion Section.

\section{Materials and Methods}

\subsection{Driving regimes of vehicles}

Four driving regimes were identified based on traction and braking force values $[1,6]$ :

Acceleration: At the beginning of the journey. It is the most power used phase. It takes from the start of the journey until cruising speed.

Cruising: This regime is cruising which characterized by constant, so zero acceleration, and, consequently, constant speedy.

Coasting: A coast phase must be added to the optimal speed profile to reduce energy consumption. Energy consumption is zero in this regime, because of no traction force is applied. All these regimes can be changed for energy minimization. Good choices for coasting points shorten traction regimes. However, it tends to increase journey time, which is constrained to schedule. So, the points in the journey where coasting should start and finish are very important ones in terms of minimizing energy consumption [7-9].

Full braking: After the coasting regime this regime starts. This phase is important because this regime uses the maximum available braking force. However, this regime's energy can be recovered as regenerative braking energy.

An optimization problem can be defined to find the least energy consumption by changing all other parameters. Speed is of great importance in the energy consumption of trains.
The reason for this is that the resistance of the train is a speeddependent parameter in the Davis Equation, which is found by empirical studies. However, if you decrease the speed too much to reduce energy consumption, you cannot travel at the desired time.

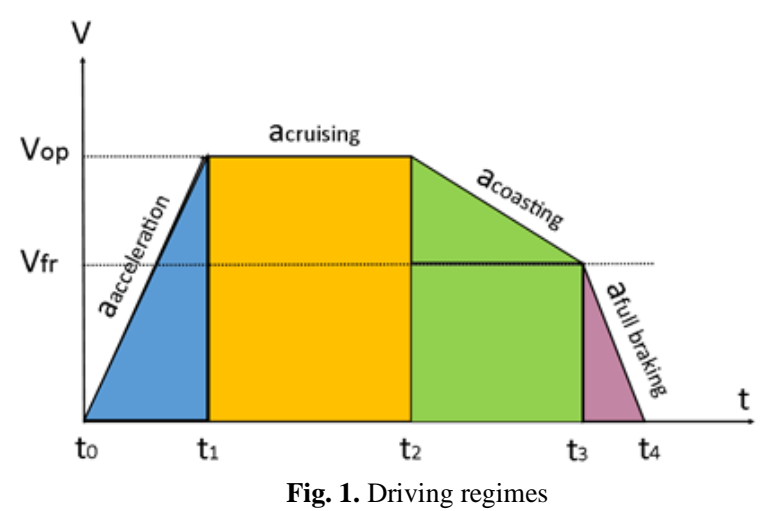

Blue: Covered distance in acceleration time

Orange: Covered distance in cruising time

Green: Covered distance in coasting time

Purple: Covered distance in full braking time

Some parameters cannot be changed here. These are $\mathrm{X}$ is the distance to cover; Vop is maximum speed and $\mathrm{t} 4$ is arrival time. Vfr also has restrictions.

Davis Equation:

$$
F_{R} A V^{2}+B V+C\left(\frac{d a N}{t o n}\right)
$$

\subsection{Particle swarm theory}

In a Particle Swarm Optimization (PSO) there are two basic points. These are particles with random positions and speeds are initiated at size D. At the same time, Dimension D is also equal to the unknown number in the conformity function. Updating its generations is the purpose to find the best value. Each particle is updated according to the two "best" values at each iteration. There are two different best values. The first is the best value a particle has ever found. This value is particle best "pbest" and it is stored in memory for use when needed. The second-best value is the real best value that any particle in the swarm has ever achieved. This value called the global best value "gbest". The speeds and positions are changed with these newly assigned values. The swarm particle matrix's size is $n \times D$. $n$ is the number of particles as shown in (2):

$$
\begin{array}{ccc}
X_{11} & \cdots & X_{1 D} \\
\vdots & \ddots & \vdots \\
X_{n 1} & \cdots & X_{n D}
\end{array}
$$

Particle updates speed and position respectively according to (3) and (4).

$$
\begin{aligned}
& \quad V_{i}^{k+1}=V_{i}^{k}+c 1 * \operatorname{rand}_{1}^{k}\left(\text { pbest }_{i}^{k}-x_{i}^{k}\right)+c 2 * \\
& \operatorname{rand}_{2}^{k}\left(\text { gbest }^{k}-x_{i}^{k}\right) \\
& x_{i}^{k+1}=x_{i}^{k}+V_{i}^{k+1}
\end{aligned}
$$


It is possible to show the described above in a figure. Figure 2 shows the working principles of the PSO.

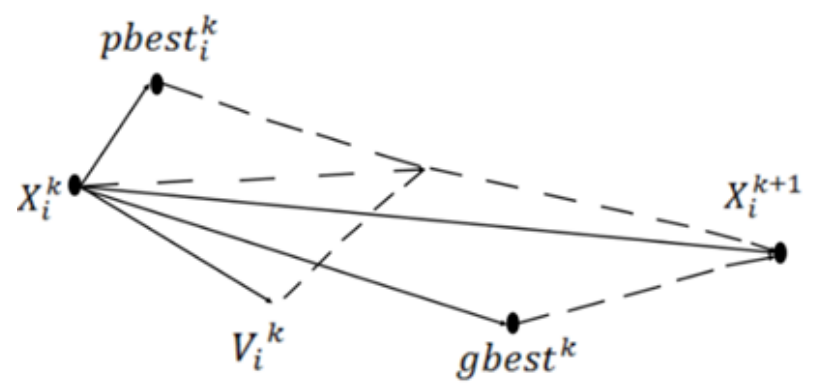

Fig. 2. Working principle of particle swarm optimization [15]

The train trip optimization is a typical multi-constrained and nonlinear optimization problem [16]. PSO Method was chosen in this study because it can easily meet these optimization problem demands.

\section{Result and Discussion}

This study aims to define a time-dependent speed optimization problem. Moreover, braking speed $\left(\mathrm{V}_{\mathrm{fr}}\right)$ is searched that satisfies the optimum speed $\left(\mathrm{V}_{\mathrm{op}}\right)$. The distance equations for the four different regimes are given by Equations (5)-(8):

$$
\begin{aligned}
& X_{1}=\frac{V_{o p}\left(\mathrm{t}_{1}-\mathrm{t}_{0}\right)}{2} \\
& X_{2}=V_{o p}\left(\mathrm{t}_{2}-\mathrm{t}_{1}\right) \\
& X_{3}=\frac{\left(V_{o p}-V_{f r}\right)\left(\mathrm{t}_{3}-\mathrm{t}_{2}\right)}{2}+V_{f r}\left(\mathrm{t}_{3}-\mathrm{t}_{2}\right) \\
& X_{4}=\frac{V_{f r}\left(\mathrm{t}_{4}-\mathrm{t}_{3}\right)}{2}
\end{aligned}
$$

The total distance that is accomplished during the trip can be expressed as in (9).

$$
\mathrm{X}=X_{1}+X_{2}+X_{3}+X_{4}
$$

If $t_{0}$ is taken as 0, then Equation (9) can be simplified as in Equation (10).

$$
\mathrm{X}=\frac{V_{o p}}{2}\left(2 \mathrm{t}_{3}-\mathrm{t}_{1}\right)+\frac{V_{f r}}{2}\left(\mathrm{t}_{4}-\mathrm{t}_{2}\right)
$$

The total distance $\mathrm{X}$ is taken as $9000 \mathrm{~m}$ and the duration of the trip is limited by 600 seconds. By these limitations, Equation (10) becomes Equation (11).

$$
18000-V_{o p}\left(2 \mathrm{t}_{3}-\mathrm{t}_{1}\right)-V_{f r}\left(600-\mathrm{t}_{2}\right)=0
$$

Equation (11) is transformed to the objective function as shown in Equation (12).

$$
\min \left(V_{o p}=\frac{V_{f r}\left(600-t_{2}\right)-18000}{2 t_{3}-t_{1}}\right)
$$

The maximum speed of the tram is limited by $20 \mathrm{~m} / \mathrm{s}$ and the braking speed is limited by $13 \mathrm{~m} / \mathrm{s}$. These limitations have turned our problem into a constrained optimization problem with the following constraints.

\section{Constraints: \\ $V_{f r} \leq V_{o p} \leq 20 \mathrm{~m} / \mathrm{s}$ \\ $0 \leq V_{f r} \leq 13 \mathrm{~m} / \mathrm{s}$ \\ $t_{1} \leq t_{2} \leq t_{3} \leq 600 \mathrm{~s}$}

The problem solved by PSO in MATLAB. Figure 3 describes the Epoch values of $\mathrm{t} 1, \mathrm{t} 2, \mathrm{t} 3, \mathrm{Vfr}$, and lastly Vop.
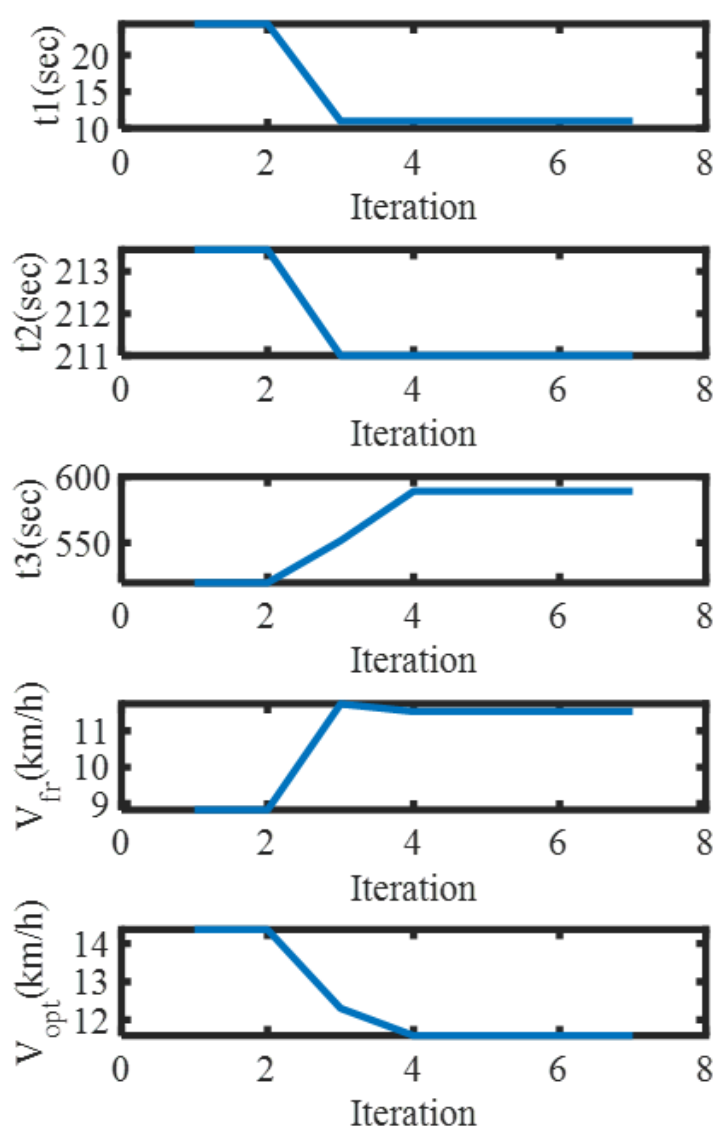

Fig. 3. Iterations of $\mathrm{t} 1, \mathrm{t} 2, \mathrm{t} 3, \mathrm{Vfr}$, and Vop by PSO

The optimum $\mathrm{V}_{\text {op }}$ speed is found as $11.5808 \mathrm{~m} / \mathrm{s}$ only in 4 iterations by choosing number of particles as 25 . The conditions that satisfy the optimum speed are found as follows:

$V f r=11.53 \mathrm{~m} / \mathrm{s}$

$t 1=11 \mathrm{~s}$

$t 2=211 \mathrm{~s}$

$t 3=589 s$

The spent time for each iteration is given by Figure 4 .

According to Figure-4, the total spent time for first four iterations is 20.8 milliseconds and the maximum spent time is seen in second iteration as 7.3063 milliseconds.

For comparison, the same problem is solved by MATLAB's own constrained nonlinear multivariable problem solver (fmincon). The obtained results are found as shown in Fig. 5. 


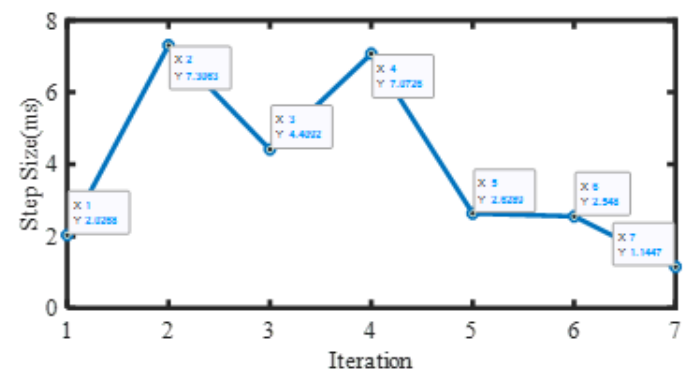

Fig. 4. Spent time for each iteration of PSO

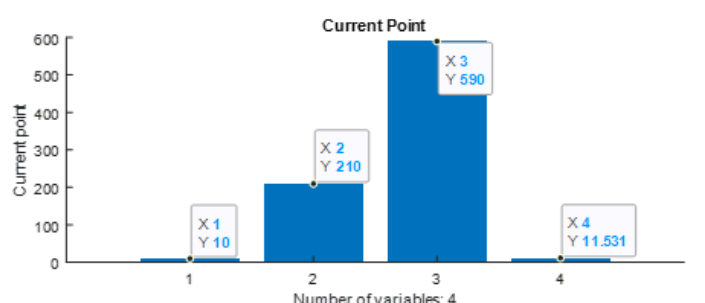

Number of variables:
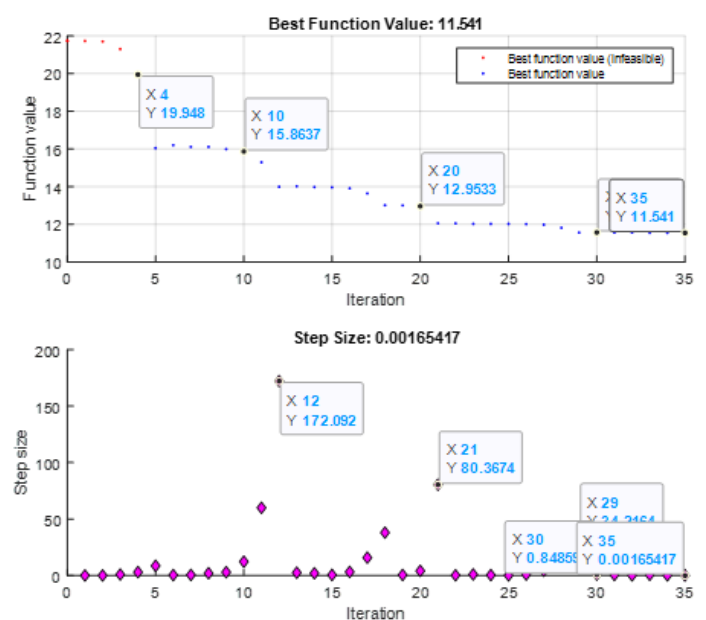

Fig.5. Iterations of $\mathrm{V}_{\mathrm{op}}$ and step size of each iteration by fmincon

The optimum $\mathrm{V}_{\text {op }}$ speed is found as $11.5410 \mathrm{~m} / \mathrm{s}$ in 35 iterations. Although the ultimate optimum $\mathrm{V}_{\text {op }}$ is less than the result found by PSO, the $\mathrm{V}_{\text {op }}$ of fmincon found at its $4^{\text {th }}, 10^{\text {th }}$ and $20^{\text {th }}$ iterations are $19.948 \mathrm{~m} / \mathrm{s}, 15.8637 \mathrm{~m} / \mathrm{s}$ and 12.9533 $\mathrm{m} / \mathrm{s}$ respectively, which are worse than the solution of PSO. The conditions that satisfy the optimum speed found by fmincon are as follows:

$V f r=11.531 \mathrm{~m} / \mathrm{s}$

$t 1=10 \mathrm{~s}$

$t 2=210 \mathrm{~s}$

$t 3=590 \mathrm{~s}$

The total spent time for 35 iterations of fmincon is 259.6 milliseconds, which is approximately 13 times of the total spent time by PSO, and the maximum spent time is seen at $12^{\text {th }}$ iteration as 172.092 milliseconds, which is approximately 23.5 times of maximum spent time in a single iteration of PSO. These results prove that PSO has less computational complexity than fmincon.

\section{Conclusion}

To minimize the $\mathrm{V}_{\text {op }}$, it is necessary to take the ending point of costing phase $\left(\mathrm{t}_{3}\right)$ as close as possible to the upper limit of itself, where the starting and ending points of the cruising phase should be as close to the lower limit of them. Experiments with PSO also have proven this situation.

Besides, $V_{\text {op }}$ itself is an upper constraint for the $V_{\text {fr }}$ in the problem. This situation turns the defined optimization problem into a recursive problem and requires sequential search steps for the optimum solution repeatedly according to suitability of the variable upper constraint of $\mathrm{V}_{\text {fr. }}$. In this study, the requirement of $\mathrm{V}_{\text {fr }}$ to be smaller than $\mathrm{V}_{\text {op }}$ can be achieved only when the upper limit of $\mathrm{V}_{\mathrm{fr}}$ was determined as $13 \mathrm{~m} / \mathrm{s}$. However, this is a subject open to development that will require further work on it.

The optimum $\mathrm{V}_{\text {op }}$ speed is found as $11.5808 \mathrm{~m} / \mathrm{s}$ only in 4 iterations by choosing number of particles as 25 for PSO. This method can obtain $\mathrm{V}_{\text {op }}$ speed between 3 and 4 epochs with 25 number of particles in different experiments. The total spent time for first four iterations is 20.8 milliseconds and the maximum spent time is seen in second iteration as 7.3063 milliseconds.

The same problem is also solved by Fmincon. The optimum $\mathrm{V}_{\text {op }}$ speed is found as $11.5410 \mathrm{~m} / \mathrm{s}$ in 35 iterations. Although the ultimate optimum $\mathrm{V}_{\text {op }}$ is less than the result found by PSO, the $\mathrm{V}_{\text {op }}$ of fmincon found at its $4^{\text {th }}, 10^{\text {th }}$ and $20^{\text {th }}$ iterations are $19.948 \mathrm{~m} / \mathrm{s}, 15.8637 \mathrm{~m} / \mathrm{s}$ and $12.9533 \mathrm{~m} / \mathrm{s}$ respectively, which are worse than the solution of PSO. The total spent time for 35 iterations of fmincon is 259.6 milliseconds, which is approximately 13 times of the total spent time by PSO, and the maximum spent time is seen at $12^{\text {th }}$ iteration as 172.092 milliseconds, which is approximately 23.5 times of maximum spent time in a single iteration of PSO. By the conclusion, it can be said that the optimum speed can be reached and thus the braking force will be minimized by keeping the acceleration, cruising, and full braking phases as short as possible and keeping the coasting phase as long as possible. In future studies, the Resistance equation specified in Equation 1 can be directly considered as an optimization problem instead of speed. The constraints defined for the variables $t_{1}, t_{2}$ and $t_{3}$ can be improved. Finally, as we have already mentioned, the PSO, Fmincon and other optimization models can be developed for this problem by including new approaches to solve the situation of $\mathrm{V}_{\mathrm{op}}$ itself constraining $\mathrm{V}_{\mathrm{fr}}$. Based on these results, innovative driving warning systems can also be developed.

\section{ORCID}

M. Sertsöz

0000-0003-1641-9191

M. Fidan

0000-0003-2883-9863 


\section{References}

[1] Fernández-Rodríguez, A., Fernández-Cardador, A. and Cucala, A.P. July 2015. Energy Efficiency In High Speed Railway Traffic Operation: A Real-Time Ecodriving Algorithm. Proceedings of the IEEE 15th International Conference on Environment and Electrical Engineering (EEEIC), 10(13), Rome, Italy, 325-330.

[2] Scheepmaker, G.M., Goverde, R.M. and Kroon, L.G. 2017. Review of Energy-Efficient Train Control and Timetabling. Eur. J. Oper. Res., 257, 355-376.

[3] Howlett, P., Milroy, I. and Pudney, P. Energy-Efficient Train Control. Control Eng. Pract., 2, 193-200, 1994.

[4] Qu, J., Feng, X. and Wang, Q. 2014. Real-Time Trajectory Planning For Rail Transit Train Considering Regenerative Energy. Proceedings of the 17th International IEEE Conference on Intelligent Transportation Systems (ITSC), 8-11 October, Qingdao, China, 2738-2742.

[5] Milroy, I.P. 1980. "Aspects of Automatic Train Control". Ph.D. thesis, Loughborough University, Leicestershire, UK.

[6] Liu, R.R. and Golovitcher, I.M. 2003. Energy-Efficient Operation Of Rail Vehicles. Transp. Res. Part A, 37, 917-932.

[7] Chang, C.S. and Sim, S.S. 1997. Optimizing Train Movements Through Coast Control Using Genetic Algorithms. IEE Proc. Electr. Power Appl., 144, 65-73.

[8] Wong, K.K. and Ho, T.K. 2004. Dynamic Coast Control of Train Movement with Genetic Algorithm. Int. J. Syst. Sci., 35, 835-846.

[9] Acikbas, S. and Soylemez, M.T. 2008. Coasting Point Optimisation For Mass Rail Transit Lines Using Artificial Neural Networks And Genetic Algorithms. IET Electr. Power Appl., 2, 172-182.

[10] Chevrier, R. Marliere, G. Vulturescu, B. and Rodriguez, J. 2011. Multi-Objective Evolutionary Algorithm For Speed Tuning Optimization With Energy Saving In Railway: Application and Case Study. RailRome, Rome, Italy.

[11] Chevrier, R. Pellegrini, P. and Rodriguez, J. 2013. Energy Saving in Railway Timetabling: A Bi-Objective Evolutionary Approach For Computing Alternative Running Times. Transp. Res. Part C, 37, 20-41.

[12] Huang, Y. Ma, X. Su, S. and Tang, T. 2015. Optimization of Train Operation in Multiple Interstations with Multi-Population Genetic Algorithm. Energies, 8, 14311-14329.

[13] Domínguez, M. Fernández-Cardador, A. Cucala, A.P. Gonsalves, T. and Fernández, A. 2014. Multi Objective Particle Swarm Optimization Algorithm For the Design of Efficient ATO Speed Profiles in Metro Lines. Eng. Appl. Artif. Intell., 29, 43-53.

[14] Keskin, K. and Karamancioglu, A. 2017. EnergyEfficient Train Operation Using Nature-Inspired Algorithms. J. Adv. Transp., Article ID 6173795, 12 pages.

[15] [15] Sertsoz, M. 2018. "Raylı Sistemlerde Güneş Enerjisi Destekli Yenilikçi Enerji Modellemesi, Optimizasyonu Ve Analizi”. Ph.D. thesis, Bilecik Şeyh Edebali University, Enerji Sistemleri Mühendisliği, Bilecik, Turkey.

[16] [16] Huang, J. Deng, Y. Yang, Q. and Sun, J. 2016. An Energy-Efficient Train Control Framework for Smart Railway Transportation. IEEE Transactions on Computers, 65(5), 1407-1417.
NOTE: This article was presented at International Conference on Advanced Technologies (ICAT'20). It was evaluated by 2 Reviewers before publish, and it has been passed all publication and evaluation processes of journal. 